\title{
Resistance of Laminated Veneer Lumber (LVL) Produced from Rubberwood, Radiata Pine and Larch Against Subterranean Termites And White Rot Fungi
}

\author{
Paridah Md Tahir ${ }^{1,2}$, Juliana Abdul Halip ${ }^{3}$ and Lee Seng Hua ${ }^{1,2 *}$ \\ ${ }^{1}$ Institute of Tropical Forestry and Forest Products, Universiti Putra Malaysia, Malaysia \\ ${ }^{2}$ Faculty of Forestry, University of Putra Malaysia, Malaysia \\ ${ }^{3}$ Department of Furniture Design and Manufacturing, University of Tun Hussein Onn Malaysia, Malaysia
}

Received: 些 May 25, 2018; Published: 眥 May 29, 2018

*Corresponding author: Lee Seng Hua, Faculty of Forestry, Institute of Tropical Forestry and Forest Products, University of Putra Malaysia, Malaysia

\begin{abstract}
Laminated veneer lumbers (LVLs) were fabricated using rubber wood, radiate pine and larch wood. Solid rubber wood was used to serve as control for comparison purpose. All of the wood samples were exposed to subterranean termites and white rot fungi for durability evaluation. The results showed that rubber wood LVL had the highest resistance against both deterioration agents in comparison to control, confirming that the resistance of non-durable wood species could be improved by converting them into LVL.
\end{abstract}

Keywords: Termites resistance; Fungal resistance; Low density wood; Hardwood; Softwood.

Abbreviations: LVL: Laminated Veneer Lumber; PF: Phenol Formaldehyde; AWPA: American Wood Preserves Association; ANOVA: Analysis of Variance; SPSS: Statistical Package for the Social Sciences.

\section{Introduction}

Improper forest management and the rapid population increment have induced the continuous growing of timber demand and subsequently led to timber resources depletion around the world. The supply of high quality raw timbers with large diameter is declining accompanied by increasing timber price due to the aforementioned matter. Rising timber costs had shifted the manufacturer's attention from solid sawn wood to engineered wood products, for example, laminated veneer lumber (LVL). In order to attain better compression and higher strength of LVL products, wood with lower range of densities are often being used. In US, LVL has been typically constructed from southern pines, western softwoods and yellow poplar [1], while in the case of Malaysia, rubber wood are the most common used materials owing to its readily availability. Never the less, one of the disadvantages of these low density wood species is their poor durability against deterioration agents such as termites and fungi. Therefore, better durability could be anticipated by converting these low density wood into LVL bonded by phenol formaldehyde (PF) resin as PF resin has long been recognized as an effective way to enhance the wood properties $[2,3]$. To the author's knowledge, there is little or no information regarding the resistance of LVLs fabricated form low density hardwood and softwoods such as rubber wood (Hevea brasiliensis), radiata pine (Pinus radiata) and larch (Larix spp.) against both subterranean termites (Coptotermes curvignathus Holmgren) and white rot fungi (Pycnoporus sanguineus. Therefore, this study evaluates and compares the biological resistance of LVLs fabricated from rubber wood, radiate pine and larch with that of solid rubber wood.

\section{Materials and Methods}

Nine-ply laminated veneer lumber (LVL) having a dimension of $200 \mathrm{~mm}$ longx $50 \mathrm{~mm}$ widthx $10 \mathrm{~mm}$ thick was supplied by Wood 
Research Institute, Kyoto. These LVLs were fabricated from rubber wood, radiata pine and larch wood using phenol formaldehyde (PF) resin as binder. Solid rubber wood was used as control in this study for comparison purpose. For resistance tests, subterranean termites (Coptotermes curvignathus Holmgren) and white rot fungi (Pycnoporus sanguineus) were used. The termites were collected from Bukit Expo, University Putra Malaysia using pine blocks as baits. A total of 40 samples, five samples for each material used, were assigned to both resistance tests (4 materials (solid rubber wood, rubber wood LVL, radiate pine LVL and larch LVL) x2 resistance tests $\mathrm{x} 5$ replicates). LVLs and solid rubber wood were cut into dimensions of $20 \times 20 \times 10 \mathrm{~mm}$ prior to the tests. Termite tests were conducted in accordance to American Wood Preserves' Association (AWPA) Standard E1-13. 200g of sterilized sand mixed with required amount of distilled water were added into a culture bottle. Each test block was exposed to approximately $1 \pm 0.05 \mathrm{~g}$ of termites comprising $10 \%$ soldiers and $90 \%$ workers. The cultured bottles were then wrapped with black paper and kept at the room temperature $\left(25 \pm 2{ }^{\circ} \mathrm{C}\right)$ for 4 weeks. The cultured bottles were examined daily to record the mortality rate of the termites. After 4 weeks of exposure to termites, the test blocks were removed and conditioned until they reached constant weight. The mass of the blocks was weighed and the percentage of weight loss was then calculated using Equation (1).

Weight loss $(\%)=\left(\left(W_{a}-W_{b}\right) / W_{a}\right) \times 100$
Where $\mathrm{W}_{\mathrm{a}}=$ conditioned weight of the test block before exposure $(\mathrm{g})$ and $\mathrm{W}_{\mathrm{b}}=$ conditioned weight of the test block after exposure $(\mathrm{g})$.

The mortality of termites was calculated using the following equation:

Mortality $(\%)=($ Number of dead termites/initial number of termites $) \times 100$

Decay resistance test against white rot fungi was carried out according to American Wood Preserves' Association (AWPA) Standard E10-12. LVLs and solid rubber wood were cut into dimensions of $20 \times 20 \times 10 \mathrm{~mm}$ prior to the test. The cut test blocks were then sterilized in an autoclave at $121^{\circ} \mathrm{C}$ for $1 \mathrm{~min}$. Next, the sterilized test blocks were placed on mycelium covered strips and kept in capped culture bottles. The culture bottles were incubated at temperature of $25 \pm 3^{\circ} \mathrm{C}$ for 12 weeks. At the end of the incubation period, the test blocks were carefully removed and the mycelium was brushed off. The blocks were then conditioned in a conditioning room and weighed once the blocks reached constant mass. The extent of the fungal attack will be expressed as percentage of weight loss using Equation (1). The effects of materials used on termites and fungi resistance were analyzed using statistical package for the social sciences (SPSS) procedure for the analysis of variance (ANOVA) at $95 \%$ confident level $(\mathrm{P} \leq 0.05)$. The significant level of the mean values was further analyzed using Duncan's multiple range tests.

Table 1: Termites' mortality rate and mean weight losses of samples against both termites and white rot fungi.

\begin{tabular}{|c|c|c|c|}
\hline Materials & Weight loss & Mortality rate & Weight loss against \\
\hline Solid rubber wood & $64.77 \pm 11.73 \mathrm{c}$ & $48.05 \pm 1.33 \mathrm{a}$ & $3.94 \pm 0.87 \mathrm{~b}$ \\
\hline Rubber wood LVL & $6.09 \pm 1.57 \mathrm{a}$ & $100.00 \pm 0.00 \mathrm{c}$ & $0.73 \pm 0.05 \mathrm{a}$ \\
\hline Radiata pine LVL & $39.64 \pm 9.33 \mathrm{~b}$ & $100.00 \pm 0.00 \mathrm{c}$ & $6.80 \pm 1.78 \mathrm{c}$ \\
\hline Larch LVL & $81.76 \pm 12.12 \mathrm{~d}$ & $50.00 \pm 1.72 \mathrm{~b}$ & $6.02 \pm 1.65 \mathrm{c}$ \\
\hline
\end{tabular}

Means followed by same letters in the same column are not significantly different at $\mathrm{P} \leq 0.05 ; \pm=\mathrm{SD}$

\section{Results and Discussion}

The average weight loss of sample blocks caused by both termites and white rot fungi are summarized in Table 1 . The mortality rate of the termites at the end of the test is also listed in the same table. From Table 1, one can see that the larch LVL had the highest weight loss against termites (81.8\%), followed by radiate pine LVL (39.6\%) and rubber wood LVL (6.1\%), while $64.8 \%$ of weight loss was recorded in solid rubber wood. It was also observed that all termites $(100 \%)$ in the culture bottles that contained rubber wood LVL and radiate pine LVL died after 4 weeks of exposure. $48 \%$ and $50 \%$ mortality rates were observed in the culture bottes that contained solid rubber wood and larch LVL, respectively, suggesting lower resistance against termite attack. Larch LVL had lost higher weight even compared to solid rubber wood, implying that larch wood is more preferred by termites and even in the presence of PF resin, it could still cause severe damage to the wood. This phenomenon could be explained by its lighter density among the materials that used in this study. Larch wood that used in this study has a density of $530 \mathrm{~kg} / \mathrm{m}^{3}$, while rubber wood and radiate pine have density of $640 \mathrm{~kg} / \mathrm{m}^{3}$ and $600 \mathrm{~kg} / \mathrm{m}^{3}$, respectively. Logically, it is much easier for the termites to nibble softer wood like larch in comparison with harder radiate pine and rubber wood. Rubber wood LVL showed the highest resistant among the three wood species used and the reason could be due to the fact that rubber wood itself contains relatively high amount of formaldehyde content [4]. It is interesting to note that the resistance to termites was prominently improved by converting solid rubber wood to LVL. The fact that rubber wood LVL is more resistance to termites could be explained by the presence of PF resin in the glue line, which imparted some preservative properties to the LVL. Poisonous nature of the phenol and the toxicity of the free formaldehyde released during the exposure period might have caused the death of the termites [5]. 
According to Table 1, surprisingly, LVL made from radiate pine and larch wood had higher weight loss against white rot fungi $(6.8 \%$ and $6.0 \%$, respectively) in comparison to rubber wood LVL and solid rubber wood. These findings were in disagreement with Nilsson [6] who suggested that the higher susceptibility of hardwoods is due to their lower lignin content compared to that of softwoods. On the other hand, rubber wood LVL revealed better performance against white rot fungi compared to solid rubber wood, with weight losses of $0.7 \%$ and $3.9 \%$, respectively. Similar to the findings against termites, the presence of PF resin might have some influence on the fungi preference. The cured PF resin is very hard and thus made it more difficult for the white rot fungi to grow on the edges of the LVL. Therefore, only the tangential surface was fully colonized by the fungi. Whilst in the solid rubber wood all of the four surfaces were colonized by the fungi resulting in more severe degradation.

\section{Conclusion}

Based on the weight loss and mortality rate, rubber wood LVL is the most resistant toward termites among the three species studied in the present work, followed by radiate pine and larch. By converting solid rubber wood to rubber wood LVL, the resistance against termites had improved approximately 10-folds owing to the presence of PF resin glue line which might have toxic effect against termites. On the other hand, both radiate pine and larch LVL are more susceptible to white rot fungi compared to that of rubber wood LVL. In the comparison between solid rubber wood and rubber wood LVL, once again, rubber wood LVL displayed better resistance against white rot fungi. Rubber wood exhibited a superior resistance ability might be due to several factors. One of the probable theories is that the rubber wood contains a substantial amount of formaldehyde which may provide a better resistance towards both termites and white rot fungi. Further study in quantify the amount of formaldehyde in all the wood species used in the study is therefore needed to be conducted to verified the above statement.

\section{Acknowledgment}

This study was financially funded by Higher Institution Centre of Excellence (HICoE), Institute of Tropical Forestry and Forest Product (INTROP), University Putra Malaysia.

\section{References}

1. Tang RC, JH Pu (1997) Edgewise bending properties of laminated veneer lumber: effect of veneer grade and relative humidity. Forest Products Journal 47(5): 64-69.

2. Zaidon A, SH Lee, AA Mohd Hafifuddin, N Muhamad Norfazimie (2015) Addition of ammonium hydroxide as formaldehyde scavenger for sesenduk (Endospermum diadenum) wood compregnated using phenolic resins. European Journal of Wood and Wood Products 74: 277280.

3. Paridah MT (1990) Synthesis and evaluation of organosolv ligninmodified phenolic resins for bonding southern pine plywood. In Sellers TJ (Ed.) Resin Adhesive Research for Wood Composites, Research Report 16, Mississippi Forest Products Utilisation Laboratory, Mississippi, USA, pp. 49.

4. Yap FP (2000) Effects of solids content of phenol formaldehyde on the properties of rubberwood OSB. Dissertation, University Putra Malaysia, Malaysia.

5. Lee SH, A Zaidon (2015) Durability of phenolic-resin-treated sesenduk (Endospermum diadenum) and jelutong (Dyera costulata) wood against white rot fungus. European Journal of Wood and Wood Products 73(4): 553-555.

6. Nilsson T (2009) Biological wood degradation. In Ek M, Gellerstedt G \& Henriksson G (eds) Wood Chemistry and Wood Biotechnology (Pulp and Paper Chemistry and Technology), $1^{\text {st }}$ edn. De Gruyter, Berlin, pp. 224.

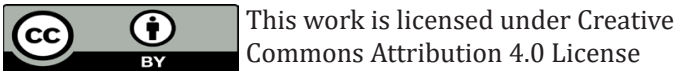

To Submit Your Article Click Here: Submit Article

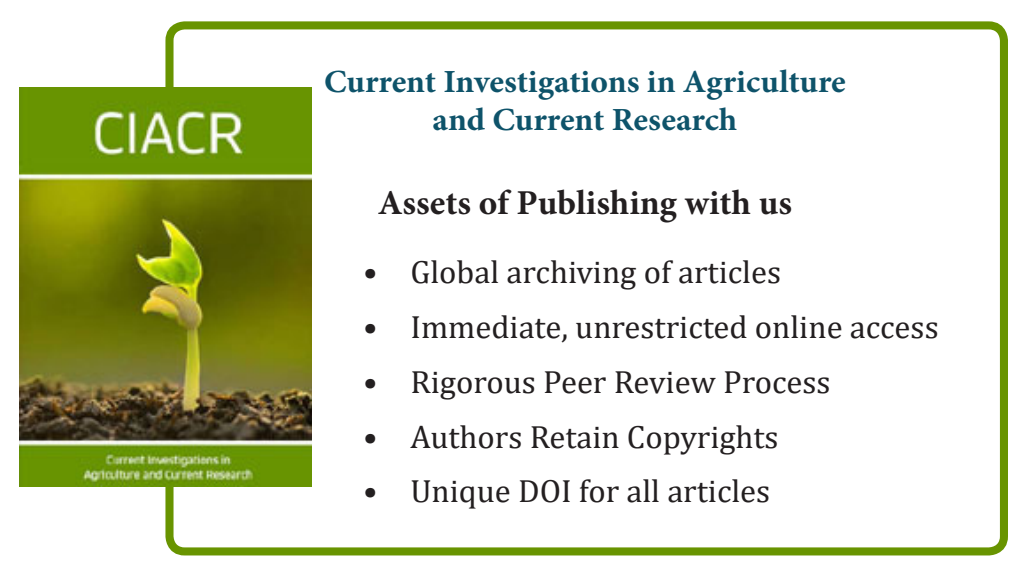

